\title{
Market Trends and Forecast of Chinese Outbound Tourism
}

\author{
Jason Li Chen ${ }^{a}$, Gang $\mathrm{Li}^{\text {a }}$, Lingyun Zhang ${ }^{\mathrm{b}}$ and Ruijuan $\mathrm{Hu}^{\mathrm{c}}$ \\ a. University of Surrey, Guildford, UK \\ b. Beijing Union University, Beijing, China
}

c. University of International Business and Economics, Beijing, China

\section{Evolution of the Chinese outbound tourism}

Over the last two decades, the global tourism destinations have witnessed a drastic growth in Chinese visitors. As the largest outbound tourism market since 2012, China remained on the top of the global spenders' list with a tourism expenditure of US\$ 129 billion in 2013, an increase of almost tenfold since 2000, when it ranked 7th. In fact, China has surpassed the second and third largest spenders the US and Germany with a gap stretched to over US\$ 42 billion in $2013^{1}$.

The initial development of Chinese outbound tourism was largely driven by the easing restrictions on foreign travel. Prior to 1983 , Chinese citizens were only allowed to travel overseas for official, education, and business purposes. As a milestone, visiting family members in Hong Kong and Macao was allowed in 1983. By 1990, travelling on package tours organised by the Chinese Travel Service (CTS) to Thailand, Singapore and Malaysia has become possible ${ }^{2,3}$. In 1997, the Approved Destination Status (ADS) scheme was officially recognised, allowing Chinese leisure travellers to join approved group tours to visit destinations where a bilateral agreement between the governments has been established ${ }^{4}$. By 1999, there were 9 nations on the ADS list, which has rapidly expanded to over 140 destinations by 2014. In addition to the ADS scheme, Chinese citizens have been also able to apply for individual visas subject to a string of conditions depending on the destinations. 
Although visa applications are still complicated, especially for residents in smaller cities and rural areas, the gradual easing of restrictions has paved the way for the surge of the Chinese outbound tourism.

Beginning in the new millennium, the mobility of Chinese people has been further bolstered by the soaring economy and a more pragmatic policy on the outbound tourism ${ }^{4}$. Since China joined the WTO in 2001, a series of regulation relaxations liberalised the tightly-controlled outbound tourism market. In 2002, the quota system controlling the travel to Hong Kong and Macao was abolished. After the outbreak of Severe Acute Respiratory Syndrome (SARS) in 2003, the Individual Visit Scheme (IVS) was launched to allow individual tourists to visit Hong Kong and Macao. Contributed by the simplification of passport applications in 2005, the number of Chinese passport holders reached 38 million in 2012, when the e-passport was introduced ${ }^{5}$. Together with other simplifying procedures in obtaining foreign currencies and visas applications, the demand for overseas travel has been further stimulated.

\section{Market trends of Chinese outbound visitors}

Beyond the dramatic surge in the visitor numbers, there have been substantial changes in the second wave of Chinese outbound tourism ${ }^{6}$. In comparison with the first batch, who have been usually stereotyped as tourists only visiting iconic attractions on overly scheduled package tours, the new Chinese tourists are more experienced and keen to explore unfamiliar destinations with diversified needs.

\subsection{More experienced travellers}

As the first wave of Chinese outbound travellers is becoming more seasoned, the market has gradually segmented into inexperienced and experienced travellers ${ }^{6}$. The inexperienced 
segment is currently predominant in the market, contributed by millions of first-time travellers every year ${ }^{7}$. As a result, most of outbound tourists still prefer travelling on package tours visiting mainstream destinations. On the other hand, the experienced travellers are inclined to accumulate unique experiences to share with peers, rather than glancing through "must-see" attractions on a packed multi-country itinerary ${ }^{6}$. The experienced segment is currently outstripped but it is estimated to expand to one third of all international trips and $40 \%$ of overall Chinese outbound expenditure by $2020^{7}$.

\subsection{Imminent growth in the foreign independent travel market}

Underlined by the significant growth of the experienced travellers, the foreign independent travel (FIT) market has shown its potential in the future Chinese outbound tourism. In the survey conducted by Hotels.com ${ }^{8}, 67 \%$ of respondents indicate their preference for making their own travel arrangements. It is arguable that there might be a gap between respondents' preference and their actual behaviour. The sampling bias in the online survey could also exaggerate the size of this market. However, the continuous increase of this percentage over the last three years suggests a clear trend of the FIT travel (from about 50\% in 2012 to 62 in 2013 and 67 in 2014) ${ }^{9,10,8}$. The increasing number of FIT travellers tend to be wealthier and travelling longer than their tour group counterparts ${ }^{8}$, which will divert the demand from short-haul destinations to medium and long-haul destinations and spreading further to the off the beat track destinations ${ }^{6}$.

\subsection{Diversified needs}

The coexistence of the demand for group tours and FIT travel in the foreseeable future creates different needs in the outbound travel market. While group tour goers still crave for iconic places, mainstream destinations are no longer on the wish lists of FIT tourists. 
Independent travellers' shopping preference has also been shifting away from mainstream brands to style ${ }^{6}$. Even within the FIT market, the independent trips are not always completely self-organised by travellers, due to obstacles such as language barriers and time cost. Parts of the arrangements such as itinerary planning, visa applications, ticket and hotel booking are still often arranged by travel agents on a case-by-case basis. The ever-evolving and diversified needs require tourism to provide customised itinerary and personalised services.

\subsection{Use of technology}

The increasingly important role of technology in tourism, such as the Internet, mobile devices, GPS, social media, augmented reality, and online review platforms, defines the era of "smart tourism". The "connected" Chinese tourists are able to travel more confidently and independently. Whist the traditional sources including travel guide books, friends and travel websites still play the most important role in travel decision making, other sources such as online review sites and social media have witnessed a steady rise over the time. Hotels.com ${ }^{8}$ find that about 53 per cent of Chinese tourists are booking their accommodation either on the web or via mobile apps. The usage of mobile apps is particularly higher for younger travellers aged under-35 and people prefer independent travel. On the other hand, the percentage of booking through travel agents has been falling.

\subsection{Demand for accessible/barrier-free tourism}

Many Chinese tourists have received good education, some have studied abroad. Speaking simple English is becoming less of problem. However, many tourists still encounter the language barrier when travelling abroad, especially in non-English speaking countries. According to Hotel.com ${ }^{8,10}$, more than $50 \%$ of travellers reported that in-house Mandarin 
speaking staff and the ability to accept Chinese payment methods, such as China Union Pay and Alipay, are the most important offering from international hotels. Providing Chinesespecific services has also been perceived as a symbol of showing respect to the Chinese culture $^{4}$, which is often expected from the tourists ${ }^{11}$. It therefore has been a phenomenon that in-house Mandarin-speaking staff are hired to engage with tourists from China. More tourism practitioners across all the tourism sectors have realised the importance of providing Chinese-specific services throughout different stages of tourist experiences, such as the offer of translated booking websites, travel guides, welcome materials, kettles, Chinese tea, Chinese TV programmes and engaging the translated online review sites and Chinese social media.

With the development of the FIT market, visa restrictions imposed by both the Chinese and foreign governments have become one of the major barriers preventing Chinese passport holders from travelling abroad. Many destinations have been keen on simplifying the procedures in visa applications. By June 2014, 49 countries and territories have agreed to provide visa-free or visa on arrival access to Chinese visitors ${ }^{12}$. Destinations such as South Korea, the US, the UK and the Schengen region have been continuously simplifying visa applications for Chinese visitors.

\section{Forecasting the demand for Chinese outbound tourism}

Riding the tide of the new wave of Chinese outbound travellers, it is vital for the tourism industry to gauge the trend of visitor arrivals for tourism destinations around the world to cope with the Chinese demand in the future. Therefore, this section aims to forecast the total Chinese outbound travellers by 2020 , as well as the arrivals to each of the international destinations. 


\subsection{Methodology}

\subsubsection{Data}

The data of visitor arrivals origin from China to 143 international destinations during the period of 1995 and 2012 were gathered from United Nations World Tourism Organization (UNWTO) ${ }^{13}$. In line with the data source, the measures of visitors may vary across destinations, including both visitor arrivals, tourist arrivals and their variations. The total numbers of Chinese outbound visitors during 1994 and 2013 were collected from CEIC ${ }^{14}$. To ensure the observations for each destination are sufficient for the modelling and forecasting purposes, when the available time series for a country or region is shorter than eight years, the destination is dropped from the analysis. This results in 111 destinations remaining for the analysis.

\subsubsection{Treatment of missing values}

Among the 111 destinations, the observations of visitor arrivals are not always available throughout the time span between 1995 and 2012. The data for 15 destinations contain missing values in the middle of the time series. In order to use the available information as much as possible, the multiple imputation (MI) method is used to deal with the missing values. Although the MI approach was initially developed to impute the non-responses in

surveys, Honaker and King ${ }^{15}$ extend the method to cope with time series and cross sectional data. In contrast with single imputation methods such as mean replacement, the MI method does not "make up" information which was originally missing. Instead, it provides measurable uncertainties caused by the missing information in the form of variance of quantities. 
The R package "Amelia II" ${ }^{16}$ is used to perform the MI procedure for each of the destinations with missing values. Following the suggestion by King et al. ${ }^{17}$, five complete data sets are generated, based on which model estimation and forecasting are carried out. The produced five sets of forecasts are then combined using the pooling method described by Rubin ${ }^{18}$ and ${ }^{19}$. Essentially, the pooled point forecasts are the means of results from the five imputations. And the combined prediction intervals account for the uncertainties from both the forecasting and the missing data in terms of the variance within each imputation and the variance between multiple imputations.

\subsubsection{Model specification}

Exponential smoothing methods have been widely used since the 1950s. However, a big limitation of these methods is the inability to produce prediction intervals. As a remedy, scholars such as Gardner ${ }^{20}$ and Hyndman et al. ${ }^{21}$ extend exponential smoothing methods to various state space models. Based on the developments in exponential smoothing methods, Hyndman et al. ${ }^{21,22}$ propose an innovations state space framework which performs particularity well in about six-period-ahead forecasts. Therefore, Hyndman's et al. exponential smoothing approach under the state space framework is employed to forecast the total Chinese outbound travellers as well as the visitor arrivals to selected 111 destinations by 2020.

According to Hyndman et al. ${ }^{22}$, a linear innovations state space model can be written as Equations (1) and (2):

$$
\begin{aligned}
& y_{t}=w^{\prime} x_{t-1}+\varepsilon_{t}, \\
& x_{t}=F x_{t-1}+g \varepsilon_{t},
\end{aligned}
$$


where $y_{t}$ is the observation of outbound visitors at time $t ; x_{t}$ is a state vector containing the unobserved components of level, trend and seasonality; t, $w, F, g$ are coefficients; and $\varepsilon_{t}$ is a white noise series. Equation (1) is the measurement equation, describing the relationship between the unobserved states $x_{t-1}$ and the observed variable $y_{t}$. Equation (2) is the transition equation, specifying the evolution of the states over time. The use of identical errors (or innovations) in these two equations makes it an innovations state space model.

Depending on the combination of different specifications of the trend component (five versions including none, additive, additive damped, multiplicative, and multiplicative damped trends), the seasonal component (three versions including none, additive, and multiplicative), and the error term (either additive or multiplicative errors), 30 different models can be specified.

To select the best-performing trend component, seasonal component and error term, Hyndman et al. ${ }^{21}$ provide a model selection procedure based on the Akaike's Information Criterion (AIC). However, as the number of observations for each destination is relatively small, the AIC-based procedures may not have sufficient data to choose the best performing model. Therefore, Hyndman et al. ${ }^{22}$ recommends using the AIC to choose amongst the linear non-seasonal models for annual time series. Following this model selection procedure, the non-seasonal model with additive trend and additive errors (known as Holt's linear model with additive errors) is selected for most destinations. The R package "forecast" ${ }^{23}$ is used to estimate the models and generate point forecasts and prediction intervals by 2020 . For destinations treated with the MI method, the combined forecasts are constructed as the final results. 


\subsection{Results and discussions}

\subsubsection{Forecasts of total Chinese outbound visitors}

As shown in Figure 1, the point forecasts of total Chinese outbound travellers are to reach 199.14 million by 2020 , doubled the number in 2013. If the growth pattern remains unchanged as observed in the historical data, the number of travellers could have a $95 \%$ of chance falling into the predictive intervals between 136.36 million and 261.91 million by 2020.

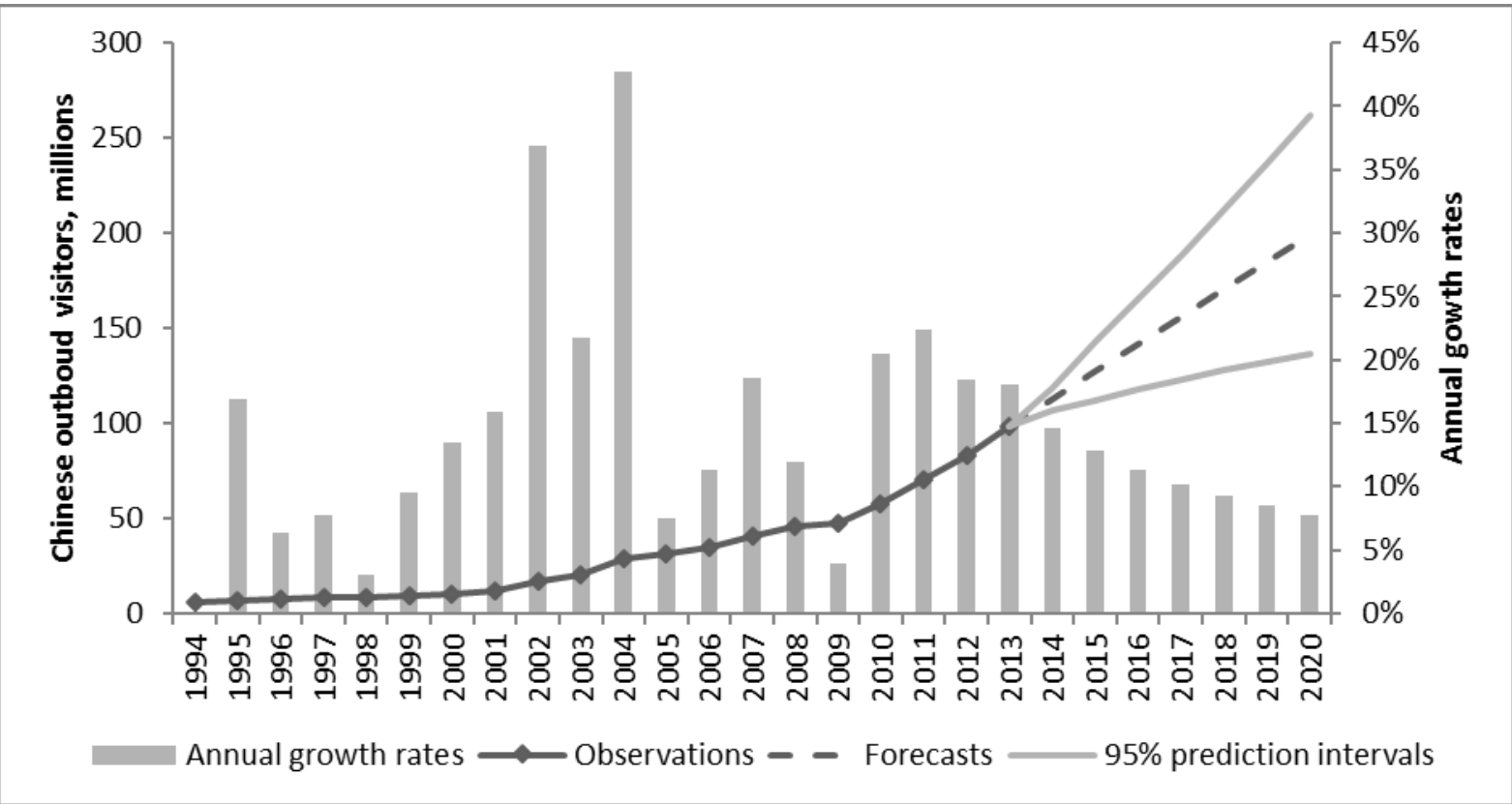

Figure 1. Actual trend and forecasts of total Chinese outbound visitors 1994-2020

The increase in China's GDP has been gradually slowing down since 2008, yet the annual growth rate still stands well above $7.7 \%$ over the last two years ${ }^{24}$. The mounting disposable income, the long-term trend of appreciation in Chinese Yuan, the expansion of transportation networks, and the easing of restrictions on overseas travel will continue to underpin the development of China as an international tourism source market. 
During the forecasting period, the gross outbound departure rate (that is the number of trips made by every 100 people) over the total population is expected to essentially double from 2013 to 2020 based on the population projection by World Bank ${ }^{25}$. Comparing with other tourism source markets, such as the UK and Canada, the outbound departure rate is still relatively low even by 2020, which implies a promising potential of the Chinese outbound tourism.

The growing needs of international travel have been met by easing restrictions and simplifying procedures. The ADS agreements with certain destinations, such as Australia, New Zealand, Japan and the US, were firstly launched as a pilot programme in first-tier cities before gradually spreading out to other regions in China. It thus can be expected that the outbound tourism demand from smaller cities will be stimulated by the progress of the ADS scheme. Individual visa applications are becoming easier and more straightforward. By June 2014,49 countries and territories have agreed to provide visa-free or visa on arrival access to Chinese visitors ${ }^{12}$.

In the meanwhile, the glooming future of advanced economies ${ }^{26}$ highlights the importance for destinations in developed countries to attract tourists, especially from the emerging markets like China. Policies such as simplifying visa applications, tailored services for Chinese visitors have been rolled out in various destinations to harvest a share of the mushrooming Chinese outbound travel market.

From 2015 to 2020, the Chinese outbound travel is predicted to increase at an average annual rate of $9.41 \%$. Due to the specification of the linear trend in the modelling, the annual growth rates of the point forecasts gradually decline over the forecasting period. The growth trend in 
Chinese outbound visitors may face uncertainties and challenges from factors such as the Renminbi exchange rates, inflation, airline fuel surcharge, competitions from domestic tourism market, and one-off events. In the first quarter of 2014, the Chinese Yuan has witnessed the biggest decline since 2005 when the new currency regime was introduced ${ }^{27}$. As the People's Bank of China, the Chinese central bank, aims to liberalise the currency within the decade, such fluctuations are expected to occur more frequently. In the meantime, the introduction of Hainan Pilot Tax Rebate Program in 2011 and the launch of Shanghai Pilot Free-Trade Zone in 2013 may partially divert tourists' shopping expenditures to the domestic market ${ }^{28}$. Hong Kong will not anymore be the only home to Disneyland attraction in the Greater China region after the launch of Disney Resort in Shanghai. The unpredictable one-off events, such as political unrests, abductions of tourists and health hazards, will also have a significant impact on specific markets in the short run. For instance, the Beijing Olympics in 2008 partially diverted or postponed the outbound demand. The outbreak of the H1N1 virus in 2009 caused a drop of trips to a number of destinations. As the uncertainties and risks in the future may break the trend captured from the historical data, the forecasting results need to be interpreted with cautions.

\subsubsection{Forecasts of Chinese outbound visitors by destination}

The point forecasts, $90 \%$ and $95 \%$ prediction intervals of Chinese visitors received by 111 international destinations are projected by 2020 . Given the limited space, only the top 20 international destinations are shown in Table 1 based on the point forecasts in 2020. The trends and forecasts of Chinese visitor arrivals to these destinations are shown in Figure 2.

Table 1 Top 20 international destinations of Chinese outbound visitors in 2020

\begin{tabular}{|c|c|c|c|c|c|}
\hline Destination & $\begin{array}{r}\text { Point forecast } \\
(000 s)\end{array}$ & $\begin{array}{l}\text { Lower limit of } \\
95 \% \text { prediction } \\
\text { intervals }(000 \mathrm{~s})\end{array}$ & $\begin{array}{l}\text { Upper limit of } \\
95 \% \text { prediction } \\
\text { intervals }(000 \mathrm{~s})\end{array}$ & $\begin{array}{l}\text { Average growth } \\
\text { rate }(2015-2020)\end{array}$ & $\begin{array}{r}\text { Rank in } \\
2012 *\end{array}$ \\
\hline
\end{tabular}




\begin{tabular}{|c|c|c|c|c|c|}
\hline Hong Kong & 22,276 & 18,346 & 26,206 & $4.59 \%$ & 1 \\
\hline Thailand & 11,079 & 4,113 & 18,046 & $13.59 \%$ & 4 \\
\hline Macao & 10,193 & 6,628 & 13,759 & $7.30 \%$ & 2 \\
\hline South Korea & 7,385 & 4,288 & 10,482 & $10.32 \%$ & 3 \\
\hline US & 4,532 & 2,405 & 6,659 & $11.64 \%$ & 7 \\
\hline Singapore & 3,023 & 1,799 & 4,248 & $4.68 \%$ & 5 \\
\hline Malaysia & 2,419 & 1,381 & 3,457 & $5.39 \%$ & 6 \\
\hline France & 2,142 & 1,504 & 2,781 & $5.05 \%$ & 10 \\
\hline Viet Nam & 1,978 & 1,022 & 2,933 & $3.88 \%$ & 8 \\
\hline Japan & 1,913 & 813 & 3,014 & $3.89 \%$ & 9 \\
\hline Indonesia & 1,575 & 1,006 & 2,144 & $9.18 \%$ & 13 \\
\hline Switzerland & 1,559 & 381 & 2,736 & $10.55 \%$ & 15 \\
\hline Australia & 1,117 & 734 & 1,500 & $6.63 \%$ & 14 \\
\hline Austria & 1,112 & 270 & 1,955 & $11.73 \%$ & 16 \\
\hline Russia & 1,068 & 927 & 1,209 & $1.99 \%$ & 11 \\
\hline Cambodia & 995 & 228 & 1,762 & $11.33 \%$ & 17 \\
\hline Germany & 965 & 679 & 1,251 & $2.93 \%$ & 12 \\
\hline Nigeria & 742 & 332 & 1,152 & $12.56 \%$ & 23 \\
\hline Maldives & 578 & 179 & 977 & $9.92 \%$ & 21 \\
\hline Canada & 567 & 310 & 825 & $7.62 \%$ & 18 \\
\hline Total Outbound & 199,139 & 136,364 & 261,914 & $9.41 \%$ & - \\
\hline
\end{tabular}

Notes: * The ranks in 2012 excludes Taiwan. In line with UNWTO ${ }^{13}$, the measures of travellers may vary across destinations (i.e., tourist arrivals at national borders for Hong Kong, Thailand, US, Malaysia and France; tourist arrivals in hotels and similar establishments for Macao; visitor arrivals at national borders for South Korea, Singapore, Viet Nam and Japan. To be consistent, they are all referred as travellers or visitors in this study.

Sharing a similar pattern with the global outbound tourism, which sees about $80 \%$ of international travel takes place within travellers' own regions, with about four out of five worldwide arrivals originating from the same region. Amongst the top ten international destinations for Chinese travellers, most are within Asia except the US and France, while more European destinations can be found from the top 20 list. Hong Kong, Thailand and Macao are predicted to be the top three most visited destinations by 2020 . The majority of the top 20 destinations in 2012 would remain attractive to Chinese travellers by 2020 . As the only exceptions, Philippines and Italy, which were ranked no. 19 and no. 20 respectively in 2012, would drop out of the 2020 list and be replaced by Nigeria and Maldives. Taiwan was ranked fifth among the global destinations in 2012, but it is not included in this study since 
the observations for Taiwan are insufficient for the forecasting. As a destination newly opened to independent mainland Chinese tourists, Taiwan has seen its tourist arrivals skyrocketed from 0.86 million in 2009 to 2.46 million in 2012, at an average growth rate of $41.89 \%{ }^{13}$. Since residents of more Chinese cities will be allowed to visit Taiwan, Taiwan is very likely to see itself as one of the major destinations by 2020 .

Compared to the ranking in 2012, Thailand is predicted to move up two places to overtake Macao's position as the second most popular destination for mainland Chinese by 2020. Both the US and France are expected to rise up two spots to 5th and 8th in the raking by 2020. Russia and Germany may slightly lose their relative popularity to Chinese tourists, whose forecasts are mainly pulled down by the slip in 2008 and 2009. The ranks for the rest of the top destinations are generally consistent with their ranks in 2012.
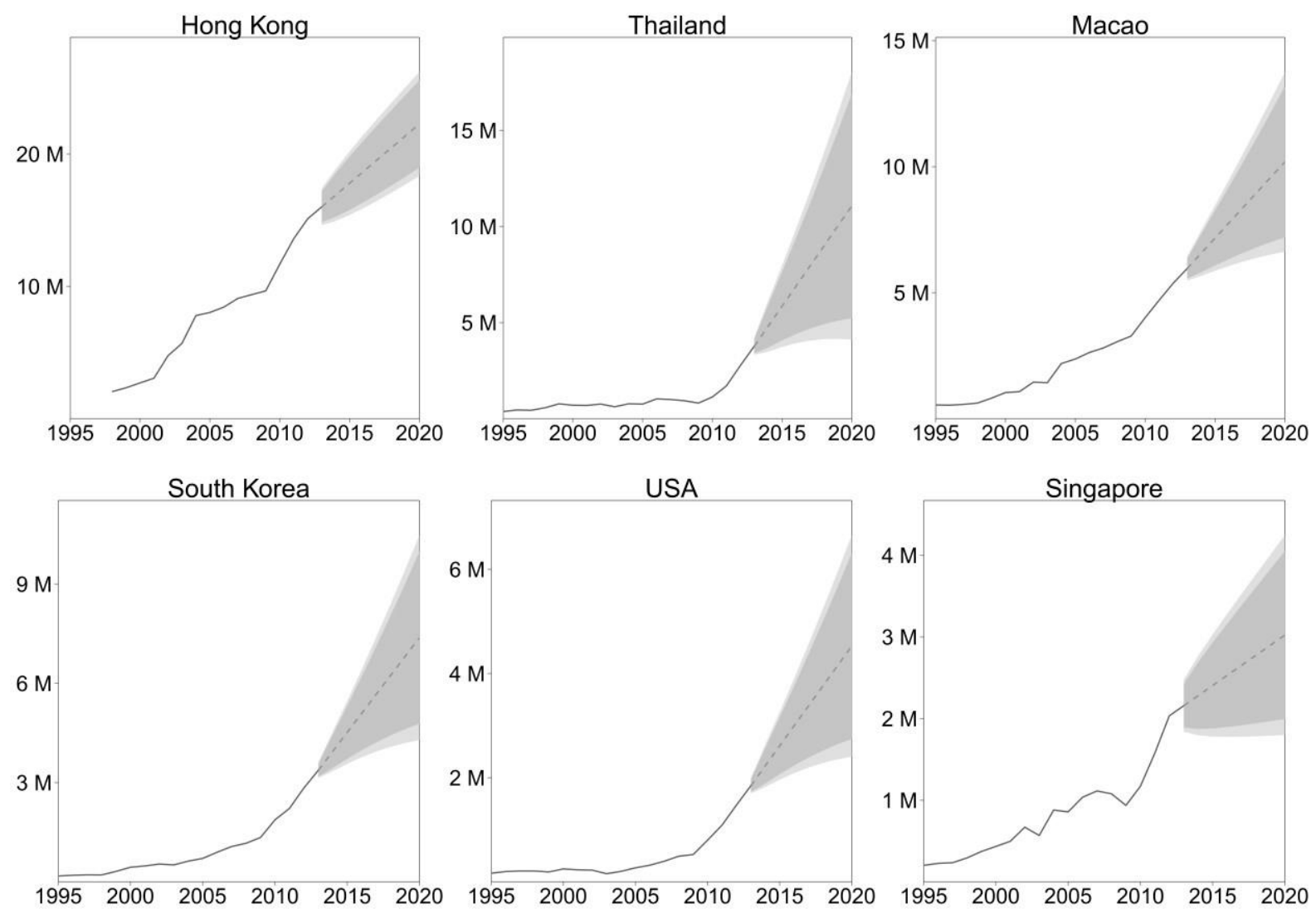

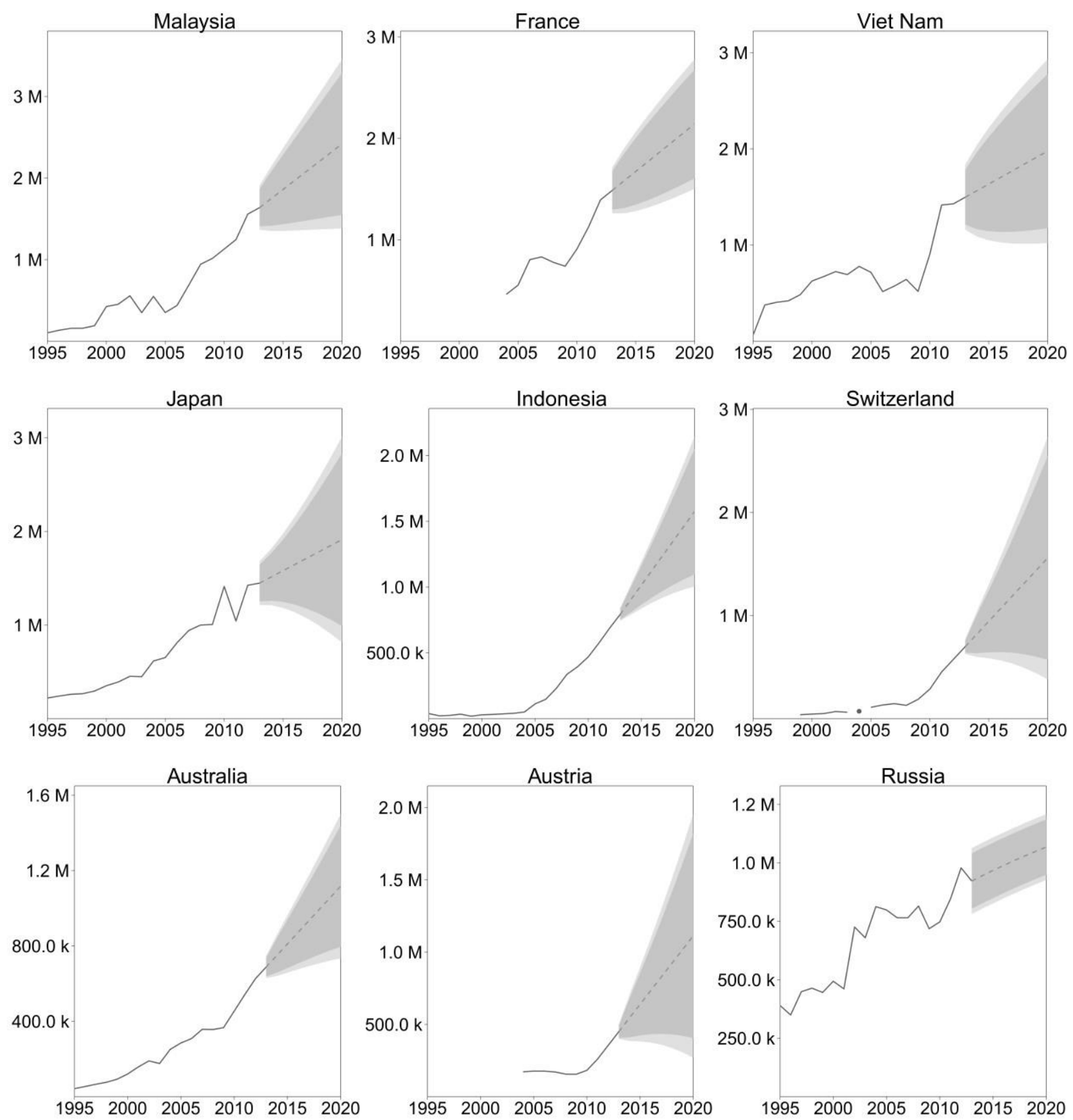

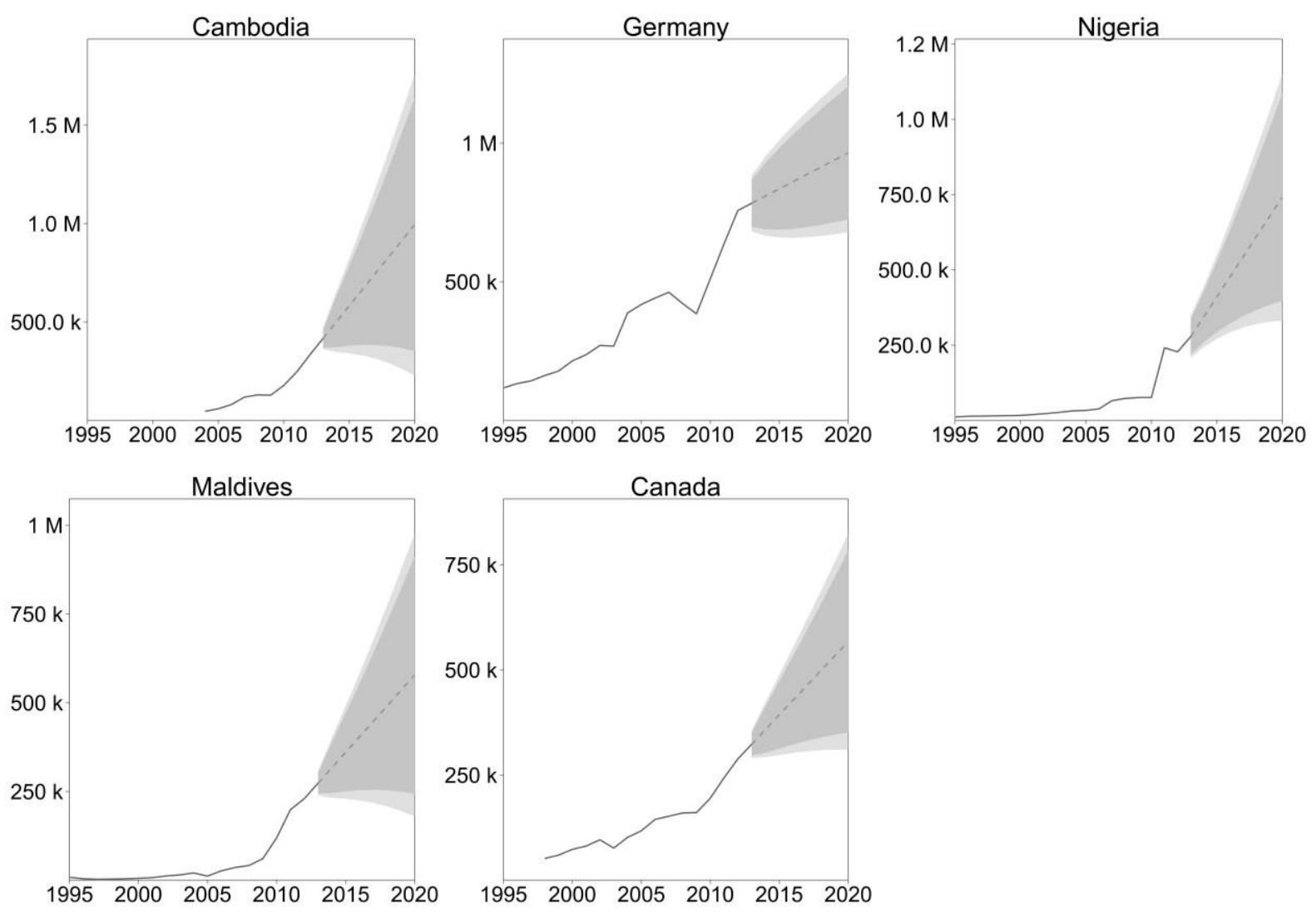

Figure 2. Top 20 destinations for Chinese outbound travellers - Actual trends, point forecasts, $90 \%$ and $95 \%$ prediction intervals $1995-2020$

\section{Asia and the Pacific}

Hong Kong is predicted to remain on top of the list of popular destinations by attracting 22.28 million Chinese tourists in 2020 , with a compound growth rate of $4.59 \%$ annually between 2015 and 2020. The $95 \%$ prediction intervals suggest that the number could go from 18.35 million up to 26.21 million. Thailand and Macao are to take the second and third places in Asia as well as over the world by 2020 , with a Chinese tourist arrivals of 11.08 million and 10.09 million, respectively. Although only attracted 439 visitors from China in 2008, Palau is likely to be the fastest growing global destination for Chinese tourists by 2020. Its visitor arrivals has soared tenfold in four years to 4,471 in 2012, thanks to the visa-on-arrival arrangement launched in 2009. If the trend continues, it is expected to receive 26.65 thousand 
Chinese travellers by 2020 with an average growth rate of $15.82 \%$ between 2015 and 2020 . Swelling annually at a compound rate of $13.59 \%$ from 2015 to 2020 , Thailand sees itself as the second largest destination as well as the second fastest growing destination for Chinese visitors in Asia Pacific, followed by Bhutan with a growth rate of $12.62 \%$ yearly.

\section{Europe}

As the top tourism destination in the world, France is estimated to remain its position as the most visited European destination by Chinese travellers, ranking the eighth amongst all international destinations by 2020. Followed by Switzerland and Austria, receiving 1.56 million and 1.11 million Chinese visitors by 2020, respectively. By ranking the growth rates in European destinations, Bosnia and Herzegovina topped the list with an average annual rate of $13.00 \%$ between 2015 and 2020. Other fast growing destinations in Europe include Slovenia, Portugal, and Austria, with a growth rate of $11.89 \%, 11.86 \%$ and $11.73 \%$, respectively.

\section{Americas}

Ranked the fifth amongst all international destinations for Chinese visitors, it is predicted that 4.53 million Chinese tourists will make their trips to the US by 2020, making the US the top destination amongst its American counterparts, distantly followed by Canada ( 0.57 million) and Brazil (0.14 million). In terms of growth rates, Paraguay is expected to be the top American destination attracting Chinese visitors with a compound rate of $14.96 \%$ per year. Followed by Cayman Islands, Bahamas and the US, with a growth rate of $13.18 \%, 12.02 \%$ and $11.64 \%$, respectively.

\section{Africa}


In the forecast results, no African destinations have yet shown its popularity by reaching the one million milestone in the market of Chinese outbound travel. The projections suggest that Nigeria, South Africa, and Angola are likely to be the most visited destination in Africa, receiving 741.82 thousand, 476.32 thousand, and 103.76 thousand Chinese arrivals by 2020 , respectively. However, as far as the growth rates are concerned, the potential can be observed from destinations such as Seychelles, South Africa, Nigeria, and Mauritius, which are expected to be growing at a fast rate of $15.10 \%, 13.01 \%, 12.56 \%$ and $11.04 \%$, respectively.

\section{Middle East}

Due to the ongoing unrest in some destinations of the region, the growth of Chinese visitors to Middle East is expected to be relatively modest. It is estimated that the top three destinations for Chinese travellers are Egypt, Saudi Arabia and Bahrain, receiving 87.89 thousand, 48.38 thousand, and 47.06 thousand visitors by 2020 from China, respectively. In terms of average annual growth rates between 2015 and 2020, Bahrain (6.70\%), Jordan (4.82\%), and Saudi Arabia (4.77\%) are predicted to be the top performers in the Middle East region.

One has to be cautious when interpreting the forecasting results due to the long forecasting horizon compared to the relatively short data span as well as the existence of missing values. The $90 \%$ and $95 \%$ prediction intervals are relatively robust forecasts, as the forecasting error and the uncertainties from multiple imputations are accounted for.

\section{Conclusions}

The emerging trends of Chinese outbound visitors impose enormous opportunities and new challenges to the global tourism industry. The potential increase of independent travellers 
means more tourism businesses in both China and international destinations are getting directly involved with Chinese visitors, who demand tailored services to go farther and experience deeper from their distinctive trips. The emerging FIT market opens up opportunities for off the beaten track destinations to share the benefit from the growing Chinese outbound travel. The era of smart tourism features the wide use of social media and mobile devices, which requires the industry to promptly adapt innovative E-business models from digital marketing and online booking to personalised customer engagement on social media and mobile platforms.

On the other hand, as pointed out by Arlt ${ }^{4}$, group tourism may still remain as a major segment of outbound tourism in a group-orientated society such as Japan and Taiwan, even if all the restrictions and barriers were lifted. The diversifications in market segmentation and tourist needs create challenges for tourism companies to achieve economies of scale, as the one-size-fits-all strategy will no longer work ${ }^{7}$. It requires the industry to develop innovative and tailored tourism products to meet different needs. Entering the new era, more destination management organisations and industry participants will be enticed by higher margins in the FIT market over the packaged tours and will join the battle on the increasingly competitive landscape to capitalise the next wave of FIT and smart tourists form China.

\section{References}

(1) UNWTO. UNWTO tourism highlights, 2014 edition; UNWTO: Madrid, 2014.

(2) Arita, S.; Croix, S. L.; Mak, J. How big? The impact of approved destination status on mainland Chinese travel abroad; Working Paper 2012-3; University of Hawaii Economic Research Organization, University of Hawaii at Manoa, 2012.

(3) China National Tourism Administration. The official ADS destinations [Online]; China National Tourism Administration, May 13, 2009. http://www.cnta.gov.cn/html/2009-5/2009-5-13-10-53-54953.html (accessed Jul 1, 2014).

(4) Arlt, W. China's outbound tourism; Routledge: London, 2006. 
(5) China.org.cn. China launches electronic passports [Online]; China.org.cn, May 16, 2012. http://www.china.org.cn/china/2012-05/16/content_25392418.htm (accessed Jul 2, 2014).

(6) Arlt, W. G. The second wave of Chinese outbound tourism. Tour. Plan. Amp Dev. 2013, 10, 126-133.

(7) Mintel. China outbound - May 2013 [Online]; Mintel Group Ltd., 2013. http://reports.mintel.com/display/718321/ (accessed Jul 21, 2014).

(8) Hotels.com. Chinese international travel monitor 2014 [Online]; Hotels.com, 2014. http://press.hotels.com/content/themes/CITM/assets/pdf/CITM_UK_PDF_2014.pdf (accessed Jul 24, 2014).

(9) Hotels.com. Chinese international travel monitor 2012 [Online]; Hotels.com, 2012. http://press.hotels.com/en-gb/files/2012/07/Hotels.com-Chinese-InternationalTraveller-MapCITM.pdf (accessed Jul 24, 2014).

(10) Hotels.com. Chinese international travel monitor 2013 [Online]; Hotels.com, 2013. http://press.hotels.com/citmcn/files/2013/08/cs4-1-9a.pdf (accessed Jul 24, 2014).

(11) Li, X.; Lai, C.; Harrill, R.; Kline, S.; Wang, L. When east meets west: an exploratory study on Chinese outbound tourists' travel expectations. Tour. Manag. 2011, 32, 741749.

(12) Ministry of Public Security of China. Destinations with visa-free and visa-on-arrival access [Online]; Ministry of Public Security of China, Posted June 27, 2014. http://www.mps.gov.cn/n16/n84147/n84196/4069471.html (accessed Jul 1, 2014).

(13) UNWTO. Outbound tourism data (calculated on the basis of arrivals data in destination countries); Dataset; UNWTO: Madrid, 2014.

(14) CEIC. Chinese outbound visitors by country [Online]; CEIC China economic \& industry data database, $2014 \mathrm{https} / / / \mathrm{www} . c e i c d a t a . c o m / e n / c o u n t r i e s / c h i n a$ (accessed Jun 10, 2014).

(15) Honaker, J.; King, G. What to do about missing values in time-series cross-section data. Am. J. Polit. Sci. 2010, 54, 561-581.

(16) Honaker, J.; King, G.; Blackwell, M. Amelia II: A program for missing data. Journal of Statistical Software 2011, 45 (7), 1-47.

(17) King, G.; Honaker, J.; Joseph, A.; Scheve, K. Analyzing incomplete political science data: An alternative algorithm for multiple imputation. Am. Polit. Sci. Rev. 2001, 95, 49-69.

(18) Rubin, D. B. Multiple imputation for nonresponse in surveys; Wiley: New York, 1987.

(19) Schafer, J. L. Analysis of incomplete multivariate data; Chapman \& Hall/CRC: Boca Raton, FL, 1997.

(20) Gardner, E. S. Exponential smoothing: The state of the art. J. Forecast. 1985, 4, 1-28.

(21) Hyndman, R. J.; Koehler, A. B.; Snyder, R. D.; Grose, S. A state space framework for automatic forecasting using exponential smoothing methods. Int. J. Forecast. 2002, 18, 439-454.

(22) Hyndman, R. J.; Koehler, A. B.; Ord, J. K.; Snyder, R. D. Forecasting with exponential smoothing the state space approach; Springer: Berlin, 2008.

(23) Hyndman, R. J.; Khandakar, Y. Automatic time series forecasting: The forecast package for R. J. Stat. Softw. 2008, 27, 1-22.

(24) World Bank. GDP growth [Online]; World Bank national accounts data, 2014 http://data.worldbank.org (accessed Jul 1, 2014).

(25) World Bank. Population estimates and projections [Online]; World Bank health, nutrition population statistics, 2014 http://datatopics.worldbank.org/hnp/Population.aspx (accessed Jul 1, 2014). 
(26) IMF. World economic outlook April 2014: Recovery strengthens, remains uneven; World economic and financial surveys; IMF: Washington, DC, 2014.

(27) BBC. The curious case of China's falling yuan [Online]; BBC News, February 28, 2014. http://www.bbc.co.uk/news/business-26385213 (accessed Jun 23, 2014).

(28) China Tourism Academy. Annual report of china outbound tourism development 2014; Tourism Education Press: Beijing, China, 2014. 